\section{4 \\ thermal \\ denaturation \\ is fundamental \\ to protein structure}

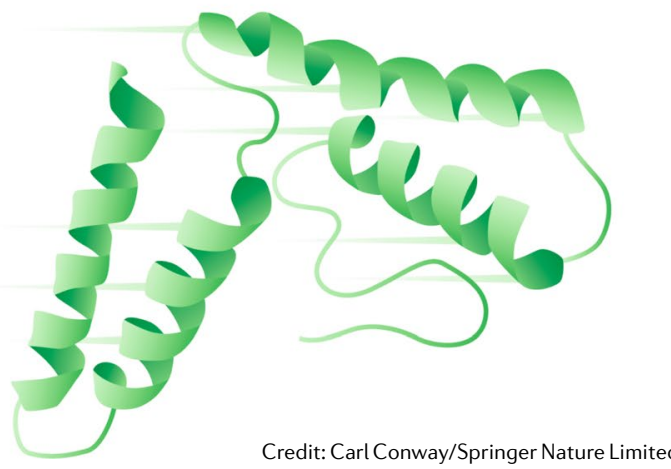

PROTEIN STRUCTURE

\title{
Unfolding in front of our eyes
}

Proteins have diverse structures because they not only occupy a large sequence space but are also dynamic - a single protein can exist in several forms with different cofactors and conformations. The thermal interconversions between these forms have traditionally been studied using methods such as protein calorimetry, a sensitive technique but not one that can provide structural information. To address this shortcoming, a team led by David Clemmer studied the $\mathrm{O}_{2}$ transport protein myohemerythrin using variable-temperature electrospray ionization-ion mobility spectrometry-mass spectrometry. They used this combined approach, described in Analytical Chemistry, to show how heating myohemerythrin can cause it to lose its cofactor, unfold and form a new S-S bond.

In humans, $\mathrm{O}_{2}$ transport is performed by haemoglobin, the $\mathrm{Fe}^{\mathrm{II}}$ site of which reversibly binds $\mathrm{O}_{2}$ to give the superoxo $\mathrm{Fe}^{\mathrm{III}}\left(\mathrm{O}_{2}\right)$. In marine invertebrates, however, this job is done by myohemerythrin, whose diiron cofactor $\mathrm{Fe}^{\mathrm{II}}(\mu-\mathrm{OH}) \mathrm{Fe}^{\mathrm{II}}$ binds $\mathrm{O}_{2}$ in the form of hydroperoxo $\mathrm{Fe}^{\mathrm{III}}(\mu-\mathrm{O}) \mathrm{Fe}^{\mathrm{III}}\left(\mathrm{O}_{2} \mathrm{H}\right)$. The lability and conformational flexibility of this unusual complex led Clemmer and co-workers to hypothesize that heating might cause the protein to transform through many states. The prospect of identifying and characterizing these states motivated the team to use methodology they had previously applied to ubiquitin, a protein that was shown to undergo thermal denaturation through several well-defined states rather than directly to a mixture of ill-defined products. Clemmer and co-workers flowed solutions of myohemerythrin through a temperature-controlled Cu block, such that the protein forms present could equilibrate before being ionized and volatilized. At each temperature, each distinct protein form can be characterized according to its drift time (related to its collision cross-section, CCS) and mass-to-charge ratio. Compared with a folded protein, an unfolded conformer will have a larger CCS and exist in a higher average charge state because the greater distances between its charged residues attenuate their repulsion. The relevance of these data to what is happening in solution is clear - the mass spectrometry-based melting point of myohemerythrin $\left(T_{\mathrm{m}} \approx 67^{\circ} \mathrm{C}\right)$ is within error of that determined using circular dichroism $\left(T_{\mathrm{m}} \approx 66^{\circ} \mathrm{C}\right)$. "We believe that thermal denaturation is fundamental to protein structure and a melting transition that resolves many conformations would provide information about side products of unfolding and how to stabilize folded structures," says Clemmer.

In all, 18 forms of myohemerythrin were observed. At low temperatures, the protein ions feature an intact $\mathrm{Fe}^{\mathrm{III}}(\mu-\mathrm{O}) \mathrm{Fe}^{\mathrm{II}}\left(\mathrm{O}_{2} \mathrm{H}\right)$ site and their low CCS values and charges suggest that they each exist as a compact four-helix bundle. Heating the protein causes it to first lose $\mathrm{O}_{2}\left(T_{\mathrm{m}} \approx 65^{\circ} \mathrm{C}\right)$ and then its diiron cofactor $\left(T_{\mathrm{m}} \approx 66^{\circ} \mathrm{C}\right)$ to give a mixture of folded and unfolded structures, the latter having high CCS values and charges. At higher temperatures, two cysteine residues undergo oxidative coupling to afford a non-native S-S bridge that stabilizes myohemerythrin in a novel folded structure.

The new methodology enables us to probe more conformations in solution and will help determine the existence and nature of relatively unstudied non-native protein states. "We're hopeful that monitoring non-native state formation with rapid and sensitive technologies is a gateway to giving meaning to what it means to be denatured," says Clemmer. Moreover, we could unravel the identities and interactions of complex cellular mixtures by using tandem mass spectrometry to identify each species present and then ion mobility spectrometry to study how its denaturation is affected by other species in the mixture.

David Schilter

ORIGINAL ARTICLE Woodall, D. W. et al. Variable-temperature ESI-IMS-MS analysis of
myohemerythrin reveals ligand losses, unfolding, and a non-native disulfide bond. Anal. Chem. https:// doi.org/10.1021/acs.analchem.9b00981 (2019) 